\title{
INVESTIGATION OF UREA USAGE IN SODA PULPING OF POPULUS DELTOIDES
}

\author{
Ehsan Yousefi, Mohammadreza Dehghani Firoozabadi \\ Gorgan University of Agriculture Sciences and Technology \\ IRAN \\ OMid GHafFarzadeH ${ }^{1,2}$ \\ 1University of Mohaghegh Ardabili \\ IRAN \\ 2TEHRAN UNIVERSITY \\ IRAN \\ Vladimír Kuňa \\ Pulp and Paper Research Institute \\ Slovak Republic \\ (Received August 2019)
}

\begin{abstract}
In this study, the use of the urea was investigated as an additive in soda pulping of Populus deltoides in comparison with the conventional soda and Kraft processes. Urea was used at the ratios of $1.5 \%, 3 \%, 4.5 \%$, and, $6 \%$ based on the dry weight of wood in the soda process. The constant factors were determined for each distinct cooking of soda, soda-urea, and Kraft treatments. The dry weight of the chips was $150 \mathrm{~g}$, the ratio of the liquor to wood (L/W) 4: 1, the maximum temperature $170^{\circ} \mathrm{C}$ and active alkaline content $18 \%$ (based on $\mathrm{Na}_{2} \mathrm{O}$ ). Cooking time, the only changing factor, was varied from 30 to 330 min depending on the type of cooking. Besides, the sulfidity ratio was $25 \%$ for all Kraft treatments. After ending pulping time, the pulp samples were fully washed. Then, the screen accepts and the screen rejects were evaluated using a 20 and a 200 -mesh screen. The observation shows that the more urea usage is in a pulping liquor, the more total yield, however, the screen reject value unexpectedly increased. Hence, the optimum values were determined by $1.5 \%$ and $3 \%$. The investigation of handsheet samples indicated an increment trend of mechanical strengths with an addition of urea; so that the tear, tensile, and burst indexes of soda-urea samples were significantly higher than for each symmetric soda sample. It has been supposed that cellulose carbamate is essential in the enhancement.
\end{abstract}

KEYWORDS: Soda pulping, Kraft pulping, urea, Populus deltoides, yield, Kappa number, rejects. 


\section{INTRODUCTION}

Many solutions to improve the pulping processes were introduced by researchers (MateosEspejel et al. 2011a,b, Ban et al. 2003). The pulping yield is a crucial point of their interest (MacLeod 2007, Tavast and Brännvall 2018). Impregnation with a high initial effective alkali concentration resulted in yield improvements by $1-1.5 \%$ units was developed by Brännvall (2018). The mildly alkaline sulfur-free technology of semi-chemical pulp production is much gentler to wood mass compared to alcaline batch (Balberčák et al. 2017). For wooden mass, the neutral sulphite cooking process, with $\mathrm{Na}_{2} \mathrm{SO}_{3}$ and $\mathrm{Na}_{2} \mathrm{CO}_{3}$ as main components of the cooking solution, is the best for the semichemical pulp quality (Balberčák et al. 2018).

In alkaline pulping process, two reactions types contributing the carbohydrates degradation: peeling off reaction and alkaline hydrolysis. The peeling off starts before $100^{\circ} \mathrm{C}$ and is intensified after the temperature. In this process, the monomers of cellulose and hemicelluloses detach from the terminal reductive aldehydes groups, individually, and decline the degree of polymerization (DP) in carbohydrates (Mozdyniewicz et al. 2013). However, it must be noted that this process is more concerned with hemicelluloses than cellulose. Alkaline hydrolysis, as the second destructive mechanism, causes occurring the fracture of cellulose chains by temperature prolongation of $140^{\circ} \mathrm{C}$. Alkaline hydrolysis has a much more negative in DP of the carbohydrates and afterwards on final sheet properties. Reaction phases of the wood constituents' degradation during cooking process was described by authors Mašura et al. (2019) and Jafari et. al. (2015). The degradation phases are also included in the theoretical model's description (Montagna et al. 2015, Nieminen 2015).

Several researches have been conducted to introduce non-sulfurous additive in alkaline pulping which resulted in presenting of some chemicals. Nevertheless, these chemicals are expensive to use (Bajpai et al. 2008). Until now, some additives, such as polysulfide (Rao and Upadhyaya 2004) and anthraquinone (Kubes et al. 1980, Francis et al. 2006) have been introduced which react in oxidative way with carbohydrates and oxide the terminal reductive aldehydes groups of the chain. On a contrary, some of them such as sodium tetraborate reduce the terminal reductive aldehydes groups (Smook 1983). Unfortunately, these chemicals are too expensive to use as digester additives. Besides, PS is not active in temperatures higher than $140^{\circ} \mathrm{C}$. In this field, urea has been declared recently in some studies as soda pulping additives, and resulted in valuable outcomes. Pang (1983) examines a method based on urea as additive in soda pulping of rice straw. The results indicated a high increase in mechanical sheet properties. He found that a new combination, namely cellulose carbamate has been obtained from the reaction between cellulose and urea, which positively affects the mechanical properties. Segal and Eggerton (1961) considered the reaction between cellulose and urea. Finally, Hebeish (1978) studied cellulose carbamate resulted from the reaction of cellulose and urea. In this study, use of the urea as an additive in soda pulping of Populus deltoides was investigated in comparison with conventional soda and Kraft processes. Urea was used at a ratio of 1.5, 3, 4.5 and 6\% based on the dry weight of wood in the soda process.

\section{MATERIALS AND METHODS}

Populus deltoides sample logs were prepared from Shast Kalateh forest, Gorgan city, Iran. The logs were cut to disks and chipped for the laboratory chipper at Gorgan University. Acceptable chips (30-40 $\mathrm{mm}$ for length and width and $2 \mathrm{~mm}$ for thickness) were sorted using by the appropriate sieve. Then, the moisture content (MC) was measured according to T 412 om-94 of TAPPI test standard method. 
All cooking processes i.e. soda, soda-urea and Kraft treatments were conducted in a 6-cylindric rotating digester which had been immersed in hot glycerin oil. The constant factors were $150 \mathrm{~g}$ of chips based on oven dry weight (L/W 4:1), maximum cooking temperature was $170^{\circ} \mathrm{C}$, and active alkaline content (for soda, soda-urea and Kraft) was $18 \%$. Variable factors, sulfidity achieved 25\% (just in Kraft cooks), addition dosage of urea was 1.5\%, 3\%, 4.5\% and 6\%, respectively (only in soda-urea cooks) and the time at maximum temperature was determined from $30 \mathrm{~min}$ to $360 \mathrm{~min}$ with a gap of $15 \mathrm{~min}$ or $30 \mathrm{~min}$ between the treatments. Meanwhile, it took about $90 \mathrm{~min}$ to reach the maximum temperature $\left(170^{\circ} \mathrm{C}\right)$ from starting point of the cooking.

After finishing all the above-mentioned cooks, the optimum pulp samples were selected for the next processes such refining, sheet preparation, and mechanical testing. It is noteworthy that the mentioned optimum samples were selected based on the primary pulp evaluations including evaluation of freeness (CSF), screen reject value - which is determined based as washing of the pulp by cold water on a 20 mesh screen and collected on a 200 mesh screen- and kappa number of the screen accepted pulp. The screen yield and moisture content were determined, as well. The pulp samples were refined using a laboratory PFI mil to achieve $400 \pm 25 \mathrm{ml}$ according to standard T 227 om-99 (Tappi 1999). Afterwards, the pulp samples were selected with a kappa number of approximate 30 . Thence, the changes for the next steps include Kraft pulp sample with time at maximum temperature of $45 \mathrm{~min}$ and sulfidity of $25 \%$, the soda pulp sample with time at maximum temperature of $150 \mathrm{~min}$, the soda- urea pulp samples with time at maximum temperature of $180 \mathrm{~min}$ with $1.5 \%$ urea addition and soda- urea pulp samples with time at maximum temperature of 240 min with $3 \%$ urea addition.

Standard handsheets $\left(60 \mathrm{~g} \cdot \mathrm{m}^{-2}\right)$ were made of the selected pulp samples according to T205 om-88 of TAPPI test methods (2002). Tensile index (TI), tear index (TI) as strength characteristics along with physical tests, e.g., thickness and bulk, were measured according to the TAPPI standard test methods. Finally, statistical analysis was conducted using SPSS software (version 16) and means were compared based on completely randomized design.

\section{RESULTS AND DISSCUSION}

The yield, screen reject, kappa number, and $\mathrm{pH}$ value have been illustrated below based as the different cooking treatments in Figs. 1 to 5.

\section{Correlation of pulping operation time and yield}

In Fig. 1, the regression relations were compared based as cooking time and the yield in the different pulping treatments.

As seen, at each specific cooking time, soda pulping process resulted in higher yield amount compared to equivalent Kraft pulping methods. Besides, with addition of urea, the yield has increased compared to the conventional soda. It seems that the addition of urea protects some of the polysaccharides against degradation, so that the reductive end groups of the carbohydrate chains were protected against peeling. Chu et al. (2008) obtained similar results as they concluded that the addition of urea to the cooking liquor of soda pulping process would increase the pulping yield. They indicated an optimal dosage of urea by 4\%. Bajpai et al. (2008) also reported that adding urea to the Kraft pulping liquor increased the yield of pulping in comparison to control sample. 


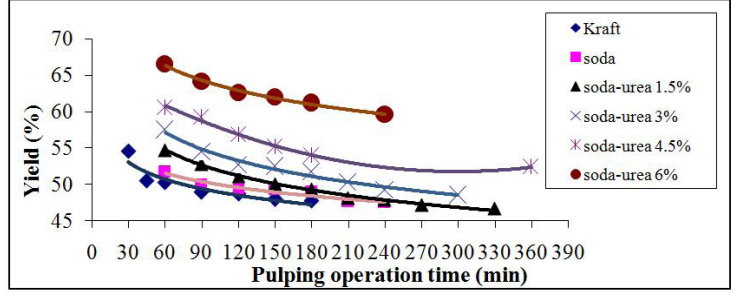

Fig. 1: Pulping operation time versus the yield.

\section{Effects of pulping operation time on screen reject}

As seen in Fig. 2, the screen rejects values have been increased by the decline in cooking time of all treatments, due to inadequate cooking time and afterwards incomplete delignification process.

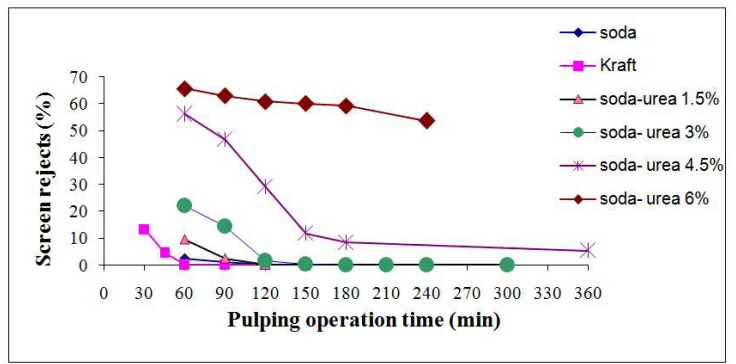

Fig. 2: Effect of cooking time on screen rejects value.

It could be evaluated through consideration of penetration and diffusion of the cooking liquor. Meanwhile, the addition of urea increased the amount of rejects and increasing the urea dosage to the cooking liquor also increased the amount of reject in all the treatments so it is not remarkable up to $3 \%$ urea, however, at levels of 4.5 and $6 \%$ urea dosage, a significant increase was observed in the reject amount.

\section{Effects of pulping operation time on kappa number}

According to Fig. 3, by increasing the cooking time, the kappa number of the pulp samples decreased causing an increase in delignification process. Also, in each individual cooking time, Kappa number was relatively higher in soda pulp samples compared to the Kraft. Meanwhile, urea addition caused the increase of the kappa number and it got intensified by the usage of higher urea dosage. It could be implicated that urea has acted as a slowing effect on delignification process. The above-mentioned results of screen reject confirm this idea. Cho et al. (2008) considered the effect urea usage in soda pulping of oak and observed that usage of urea caused the retained lignin to increase. This result is in consistent with the present study. In contrary, Bajpai et al. (2008) illustrated that urea usage in dosages of $0.05 \%$ and $0.075 \%$ had no significant effects on amount of the retained lignin in Kraft pulping of Eucalyptus. 


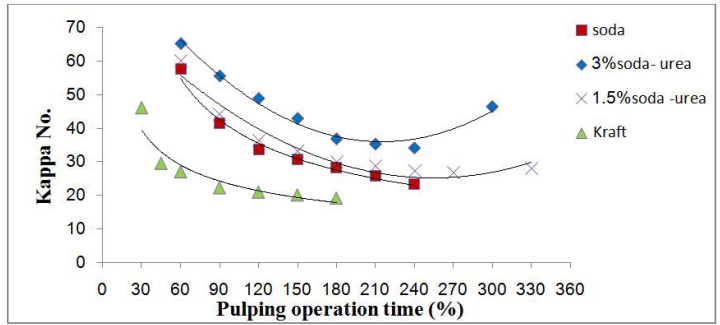

Fig. 3: Effect of pulping operation time on kappa number.

\section{Correlation of pulping operation time and $\mathrm{pH}$}

As shown in Fig. 4, with increasing the cooking times, the $\mathrm{pH}$ of black liquor decreased which is due to the use of chemical reagents by the chips. As a matter of fact, by increasing of the operation time, it is expected to increase the rate of delignification process and decrease the pulp kappa number. In this case, a reverse trend has been observed in the treatments with much higher time in cooking operation (especially in the soda-urea treatments). In fact, by the passage of time after a determined point, the chemical reagents are finished because of impeccable consumption by the raw materials, and that it is no longer possible to pursue the delignification. Hence, the cooking operation must be hampered to avoid the unwanted reaction, e.g., condensation. The higher relative kappa number of the pulp samples is in consistence with this result (Fig. 4 and Tab. 1).

Tab. 1: Correlation of pulping operation time and $p H$.

\begin{tabular}{|c|c|c|c|c|c|c|}
\hline $\mathbf{T}^{* * *}$ & Soda & $\begin{array}{c}\text { Soda-urea } \\
\mathbf{1 . 5 \%}\end{array}$ & $\begin{array}{c}\text { Soda-urea } \\
\mathbf{3 \%}\end{array}$ & $\begin{array}{c}\text { Soda-urea } \\
\mathbf{4 . 5 \%}\end{array}$ & $\begin{array}{c}\text { Soda-urea } \\
\mathbf{6 \%}\end{array}$ & Kraft \\
\hline 30 & - & - & - & - & - & 10.66 \\
\hline 45 & - & - & - & - & - & 10.66 \\
\hline 60 & 13 & 12.92 & 12.84 & 13.26 & 13.91 & 10.66 \\
\hline 90 & 12.94 & 12.83 & 12.72 & 12.96 & 13.27 & 10.66 \\
\hline 120 & 12.83 & 12.74 & 12.62 & 12.83 & 13.1 & 10.66 \\
\hline 150 & 12.84 & 12.7 & 12.42 & 12.6 & 12.8 & 10.66 \\
\hline 180 & 12.78 & 12.62 & 12.27 & 12.48 & 12.61 & 10.66 \\
\hline 210 & 12.69 & 12.58 & 12.21 & - & - & - \\
\hline 240 & 12.09 & 12.46 & 12.14 & - & 10.66 & - \\
\hline 270 & - & 11.56 & - & - & - & - \\
\hline 300 & - & - & 10.8 & - & - & - \\
\hline 330 & - & 11.31 & - & - & - & - \\
\hline 360 & - & - & \multicolumn{7}{l}{} \\
\hline
\end{tabular}




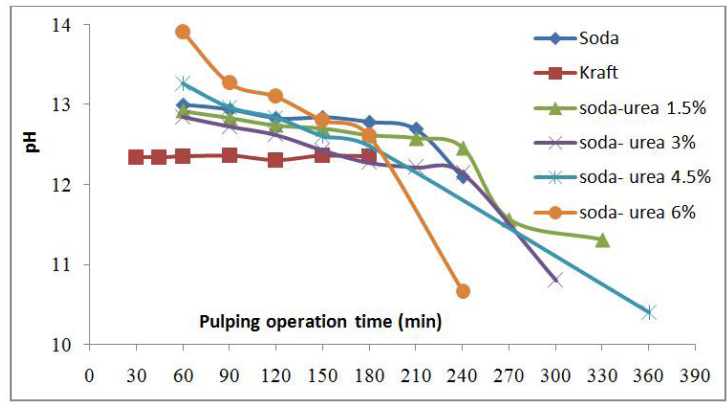

Fig. 4: Correlation of pulping operation time and $\mathrm{pH}$.

\section{Correlation of yield and Kappa number}

Fig. 5 shows the relation between Kappa number and yield for the soda, soda-urea and Kraft treatments. It could be realized that in each equivalent kappa number, the yield of Kraft and soda treatments are the highest and lowest amount, respectively. And the yield of soda-urea treatments is between them. It could be found that addition of urea decreased the delignification rate. The increment of Kappa number in the treatments with higher yield is in consistence with this idea. It may be about higher retained lignin in the soda-urea pulp samples compared with soda ones.

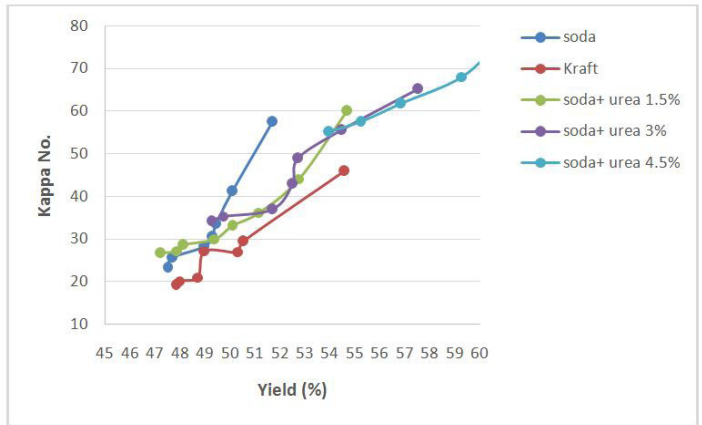

Fig. 5: Correlation of yield and Kappa number in soda, soda-urea 1.5\%, soda-urea 3\%, soda-urea 4.5\%, and Kraft.

\section{Drainage index}

All the pulp samples were refined using a laboratory PFI mill to achieve the drainage index of $400 \pm 25 \mathrm{ml} \mathrm{CSF}$ according to standard T 227 om-99 (Tappi 1999). In this case, the soda, soda with $1.5 \%$ urea, soda with $3 \%$ urea, and Kraft pulp samples required about 11000, 10000, 10000, and $12000 \mathrm{rpm}$. Overall, the results of drainage index showed that:

- Kraft and soda pulp samples require the highest and lowest intensity of refining, respectively,

- Addition of urea to pulping liquor caused a decrease in the refining intensity,

- There was not a significant difference between the additions of different dosage of urea.

Cho et al. (2008) observed that urea addition in soda pulping of Oak lessened the intensity of refining. In contrast, Kraft pulp samples required lower relative refining intensity. In another study, the addition of urea was considered in Kraft pulping of eucalyptus to facilitate the refining process with a decreasing effect on refining intensity (Bajpai et al. 2008). 


\section{Characterization of paper sheets}

The results of mechanical properties of paper sheets from soda, Kraft, and soda-urea pulp samples are illustrated in Tab. 2. In this case, tensile, burst, and tear indexes have been measured.

Tab. 2: The sheet evaluation results of mechanical properties.

\begin{tabular}{|c|c|c|c|}
\hline Treatments & Tensile index $\left(\mathrm{Nm} \cdot \mathrm{g}^{-1}\right)$ & Burst index $\left(\mathrm{KPa} \cdot \mathrm{m}^{2} \cdot \mathrm{g}^{-1}\right)$ & Tear index $\left(\mathrm{mN} \cdot \mathrm{m}^{2} \cdot \mathrm{g}^{-1}\right)$ \\
\hline Soda & $55.98 \mathrm{c}$ & $4.47 \mathrm{~d}$ & $4.58 \mathrm{~d}$ \\
\hline Kraft & $76.03 a$ & $6.35 \mathrm{a}$ & $6.97 \mathrm{a}$ \\
\hline Soda with $1.5 \%$ urea & $65.05 \mathrm{~b}$ & $5.67 \mathrm{~b}$ & $6.05 \mathrm{~b}$ \\
\hline Soda with $3 \%$ urea & $62.07 \mathrm{~b}$ & $6.14 c$ & $6.6 \mathrm{c}$ \\
\hline
\end{tabular}

$\mathrm{a}, \mathrm{b}, \mathrm{c}$ and $\mathrm{d}$ illustrate the significant difference.

As seen in Tab. 2, the addition of the urea to the pulping liquor causes improvement in the strength indexes of the sheets. In this case, soda-urea treatments showed better mechanical properties compared to the conventional soda. Perhaps, it is rooted from the carbohydrate protection effect by urea against peeling reactions. The higher amount of binding properties, i.e. tensile and burst, emphasizes the claim that the final reductive groups of the carbohydrates were protected.

The mechanical properties of handmade sheets were evaluated. The results indicated that addition of urea up to $3 \%$ caused to an increase in mechanical properties of the conventional soda pulp samples. This result is in consistence with the pulp evaluation properties i.e. yield reject and kappa number of the pulp. It is supposed that the urea addition induced production of cellulose carbamate which had a remarkable effect on the carbohydrate production. In fact, the final reductive groups of the carbohydrates are protected against peeling reaction by the urea. The eventual cellulose derivatives are carbamates that formed due to the reaction of free hydroxyl groups with isocyanic acid (HNCO) released in the urea degradation under alkaline conditions (Warner 1942):

$$
\begin{array}{ll}
\mathrm{NH}_{2}-\mathrm{C}(\mathrm{O})-\mathrm{NH}_{2}+\mathrm{OH}_{-} & \mathrm{OCN}-+\mathrm{NH}_{3}+\mathrm{H}_{2} \mathrm{O} \\
\mathrm{Cell}-\mathrm{OH}+\mathrm{HN}=\mathrm{C}=\mathrm{O} & \text { Cell-O-C }(\mathrm{O})-\mathrm{NH}_{2}
\end{array}
$$

Reaction of urea with cellulose in an aqueous medium at different temperatures has been widely studied by many researchers for the modification of cellulose textile finishing (Hebeish et al. 1978, Nozawa and Higashide 1981) and the improving mechanical properties of paper Segal and Eggerton (1961). While at $100^{\circ} \mathrm{C}$ hydrogen bonds between urea and cellulose hydroxyls took place, at $150^{\circ} \mathrm{C}$ the system was very complex, since crosslinking of cellulose, cellulose derivatives of urea, dimerization, as well as decomposition of urea could be realized. It was also reported that urea reacted with alcohols and polyhydric alcohols to bring about the corresponding carbamate esters Segal and Eggerton (1961). There would be some possibility that carbamates and cellulose carbamates derived during cooking consumed the alkali. It was not known why woodmeal consumed so much chemicals in the presence of urea compared to the wood chips. The reaction of cellulose with urea and substituted urea has been studied by Nozawa and Higashide (1981). They indicated the absorption band at $1710 \mathrm{~cm}^{-1}$ which the spectrum came to the same as that of the carbamate groups on the cellulose.

Cho et al. (2008) indicated that addition of urea in low alkali charge retarded delignification rate. But in high alkali application, delignification had been enhanced. Besides, the final $\mathrm{pH}$ was abruptly reduced for the $\mathrm{NaOH}$-urea cooking just in low alkali charge. 
On contrary, there was not a significant difference between $1.5 \%$ and $3 \%$ of the urea dose. Cho et al. (2008) considered the effects of urea addition by $4 \%$ in soda pulping of oak, and observed positive effects in this case. Based as their results, tensile, burst and tear indexes increased about $12 \%, 13 \%$, and $20 \%$ compared to the conventional soda pulp samples. Similarly, the produced sheets from Kraft-urea pulp samples had 14\%, 15\%, and 22\% increment in comparison with the conventional soda. Also, Bajpai et al. (2008) observed the same results in urea treatment in Kraft pulping of eucalyptus. It has been illustrated that the urea treated samples showed better amount in tensile, burst and tear indexes. The increased amounts were about 6-7\%, 6-13\% and 3-5\% for the abovementioned properties, respectively.

\section{CONCLUSIONS}

In this study, the use of urea was investigated as an additive in soda pulping of Populus deltoides in comparison with conventional soda and Kraft processes. After ending pulping operation, the pulp and paper properties, yield, kappa number and mechanical indexes were evaluated. It has been observed that the more is the urea usage in pulping liquor, the more total yield, however, the screen reject value unexpectedly increased. At a same time in pulping operation, the pulping yield evaluation showed that soda pulping method produces more yield, nonetheless, the yield of Kraft pulping method leads to achieve higher amount at a same kappa number. Correspondingly, the soda- urea pulp samples illustrated a similar result as soda- urea method led to a higher amount in the pulp yield at same time of the pulping operation. By contrast, soda-urea pulp samples require more time to achieve the same kappa number compared with the Kraft. This might be pertinent to lower yield of soda and soda-urea pulp in comparison to the Kraft. It has been imagined that utilization of urea caused to decline the delignification rate in pulping process. The investigation of sheet samples showed an increasing trend of mechanical strengths as the tear, tensile and burst indexes of soda-urea samples were significantly more than each symmetric soda sample.

\section{REFERENCES}

1. Bajpai, P., Tripathi, S., Sharma, N., Mishra, O., Bajpai, P., 2008: Use of urea an additive in Kraft pulping of eucalyptus. TAPPI Engineering, Pulping \& Environment conference, Oregon, pp 1-8.

2. Balberčák, J., Ihnát, V., Boháček, S., Medo, P., Lubke, H., 2017: Chemical processing of waste wood based agglomerates. Part I: Evaluation of properties of fluting liners made of semichemical pulp obtained by a mildly alkaline sulfur-free cooking process. Wood Research 62(5): 715-726.

3. Balberčák, J., Ihnát, V., Boháček, S., Pažitný, A., Lubke, H., 2018: Chemical processing of waste wood based agglomerates. Part II: Evaluation of properties of fluting liners made of semichemical pulp obtained by alkaline cooking process. Wood Research 63(1): 35-44.

4. Ban, W., Wang, S., Lucia, L.A., 2003: The relationship of pretreatment pulping parameters with respect to selectivity: optimization of green liquor pretreatment conditions for improved kraft pulping. Paper and Timber 85(7): 1-7.

5. Brännvall, E., 2018: Increasing pulp yield in Kraft cooking of softwoods by high initial effective alkali concentration (HIEAC) during impregnation leading to decreasing secondary peeling of cellulose. Holzforschung 72(10): 819-827. 
6. Francis, R.C., Shin, S.J., Omori, S., Amidon, T.E., Blain, T.J., 2006: Soda pulping of hardwoods catalyzed by anthraquinone and methyl substituted anthraquinones. Journal of Wood Chemistry and Technology 26(2): 141-152.

7. Hebeish, A., Waly, A.I., Abou-Zeid, N.Y., and El-Alfy, E.A. 1978. Studies on cellulose carbamate: Part I: Reaction of cellulose carbamate with aromatic amines. Textile Research Journal 48(8): 468-472.

8. Cho, N.S., Matsumoto, Y., Cho, H.Y., Shin, S.J., Ohga, S., 2008: Effect of urea addition on soda pulping of oak wood. Journal of the Faculty of Agriculture Kyushu University 53(1): $1-5$.

9. Jafari, V., Nieminen, K., Sixta, H., van Heiningen, A., 2015: Delignification and cellulose degradation kinetics models for high lignin content softwood Kraft pulp during flowthrough oxygen delignification. Cellulose 22(3): 2055-2066.

10. Kubes, G.J., Fleming, B.I., MacLeod, J.M., Bolker, L.I., 1980: Alkaline pulping with additives. A review. Wood Science and Technology 14: 207-228.

11. MacLeod, M., 2007: The top ten factors in Kraft pulp yield. Paper and Timber 89(4): 1-7.

12. Mateos-Espejel, E., Savulescu, L., Paris, J., 2011a: Base case process development for energy efficiency improvement, application to a Kraft pulping mill. Part I: definition and characterization. Chemical Engineering Research and Design 89(6): 742-752 .

13. Mateos-Espejel, E., Savulescu, L., Paris, J., 2011b: Base case process development for energy efficiency improvement, application to a Kraft pulping mill. Part II: Benchmarking analysis. Chemical Engineering Research and Design 89(6): 729-741.

14. Mašura, V., Balberčák, J., Kuňa, V., Mikulášik, R., 2019: Reaction phases of the wood constituents' degradation during Kraft cooking of spruce chips. Wood Research 64(6): 975-985.

15. Mozdyniewicz, D.J., Nieminen, K., Sixta, H., 2013: Alkaline steeping of dissolving pulp. Part I: Cellulose degradation kinetics. Cellulose 20(3): 1437-1451.

16. Montagna, P., Nieminen, K., Inalbon, M., Sixta, H., Zanuttini, M., 2015: Profiles of alkali concentration and galactoglucomannan degradation in Kraft impregnation of Scots pine wood: Experimental observations and modeling. Holzforschung 70(1): 1-9.

17. Nieminen, K., 2015: Towards a comprehensive model for cooking processes. Doctoral dissertations 225/2015. Aalto University, 85 pp.

18. Nozawa, Y., Higashide. F., 1981. Partially carbamate reaction of cellulose with urea. Journal of Applied Polymer Science 26(6): 2103-2107.

19. Rao, S.A, Upadhyaya, J.S., 2004. Studies on polysulfide pulping of Populus deltoides. Journal of Scientific \& Industrial Research 63(10): 820-825.

20. Segan, L., Eggerton, F., 1961: Some aspect of reaction between urea and cellulose. Textile Research Journal 31(5): 460-471.

21. Smook, G.A., 2016. Handbook for pulp and paper technologists (3rd edition). Tappi, The Smook book series, $520 \mathrm{p}$.

22. Tappi, 1999: T 227 om-99: Freeness of pulp. Canadian standard method, 9 pp.

23. Tappi, 2002: T205 sp-02: Forming handsheets for physical tests of pulp. TAPPI test methods, 9 pp.

24. Tavast, D., Brännvall, E., 2018: Increased pulp yield by prolonged impregnation in softwood Kraft pulping. Nordic Pulp \& Paper Research Journal 32(1): 14-20.

25. Warner, R.C., 1942: The kinetics of the hydrolysis of urea and of arginine. Journal of Biological Chemistry 142: 705-723. 
Ehsan Yousefi, Mohammadreza Dehghani Firoozabadi

Gorgan University of Agriculture Sciences and Technology

Faculty of Wood and Paper Engineering

4918943464 Gorgan

IrAN

\section{Omid Ghaffarzadeh ${ }^{1,2 *}$ \\ 1University of Mohaghegh Ardabili}

Faculty of Agriculture Sciences and Natural Resources

56rig9-il367 Ardabil

IRAN

2TEhran University

Faculty of Natural Resources

7787 I-31587 TEHRAN

IRAN

*Corresponding author: omid_ghafarzade@yahoo.com

Vladimír Kuña

Pulp and Paper Research Institute

Dúbravská Cesta i4

84I O4 Bratislava

Slovak Republic 